\title{
E se Deus fosse um ativista dos direitos humanos?
}

SANTOS, Boaventura de Sousa. Se Deus fosse um ativista dos direitos humanos. São Paulo: Cortez, 2013.

\section{Éverton Garcia da Costa*}

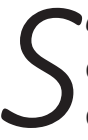
Deus fosse um ativista dos direitos humanos parte da constatação de que os direitos humanos - enquanto linguagem de dignidade humana - gozam hoje de uma hegemonia incontestável. O grande problema, conforme as palavras do próprio autor, consiste no fato de que "[...] a grande maioria da população mundial não é sujeito de direitos humanos. É objeto de discurso de direitos humanos" (p. 15). Nesse sentido, Boaventura de Sousa Santos levanta os seguintes questionamentos: até que ponto os direitos humanos contribuem eficazmente para as lutas dos excluídos e dos explorados ou, de forma contrária, tornam essa luta diária ainda mais difícil? A hegemonia atual dos direitos humanos deve ser vista como vitória histórica ou como derrota histórica? No mesmo sentido, cabe fazer ainda as seguintes indagações:
Se os direitos humanos, mesmo sendo parte da mesma hegemonia que consolida e legitima a sua opressão, não poderão ser usados para a subverter? Ou seja, poderão os direitos humanos ser usados de modo contra-hegemônico? Em caso afirmativo, de que modo? Estas duas perguntas conduzem a duas outras. Por que há tanto sofrimento humano injusto que não é considerado uma violação dos direitos humanos? Que outras linguagens de dignidade humana existem no mundo? E se existem, são ou não são compatíveis com a linguagem dos direitos humanos? (p. 17).

Para problematizar essas e outras questões relativas à hegemonia dos direitos humanos na sociedade contemporânea, o autor divide a obra em seis capítulos, aos quais são acrescentados introdução e conclusão.

Na introdução, Santos destaca a necessidade de se superar quatro ilusões que rondam os direitos humanos. A primeira delas - a ilusão teleológica - consiste na aparente universalidade e naturalidade dos direitos humanos na sociedade. No entanto, o autor mostra que por traz dessa aparente ilusão, os direitos humanos revelam-se uma construção discursiva historicamente datada: a partir do século XVIII, momento em que a utopia oriunda da ideia de emancipação política passa a ser substituída pelo conceito de direitos. A segunda ilusão, por sua vez, é o triunfalismo, ou seja, a crença segundo a qual os direitos humanos são um bem incondicional e

* Doutorando pelo Programa de Pós-Graduação em Sociologia da Universidade Federal do Rio Grande do Sul. Bolsita Capes. <eve garcia.costa@gmail. com>. 
1. Como exemplo histórico, Santos destaca a invasão de Napoleão ao Egito, ação justificada rigorosamente em um discurso sobre direitos humanos. que todas as outras linguagens de dignidade humana Ihes são inferiores em termos éticos e políticos. Por um lado, essa perspectiva ingenuamente evolucionista parece esquecer-se de que os ideais apregoados pelos direitos humanos muitas vezes foram reforçados pelo uso brutal das armas. Por outro lado, essa perspectiva também não considera - ou concebe como inferiores - a existência de outras gramáticas de dignidade humana, tais como o socialismo, o comunismo, o nacionalismo e a revolução.

A terceira ilusão que ronda os direitos humanos é a descontextualização. Segundo Santos, é "reconhecido que os direitos humanos, como linguagem emancipatória, provêm do lluminismo do século XVIII, da Revolução Francesa e da Revolução Americana" (p. 19). Todavia, o que também deveria ser reconhecido é o fato de que desde então os direitos humanos têm sido utilizados como arma política em diversos contextos, sendo operados não raramente para legitimar práticas opressivas e contrarrevolucionárias ${ }^{1}$. Além disso, se o surgimento dos direitos humanos está intimamente vinculado às duas grandes revoluções do século XVIII, a partir de meados do século XIX, no entanto, os discursos de direitos humanos passaram a ser hostis a quaisquer tentativas de transformação radical da sociedade.

Por fim, a quarta ilusão - o monolitismo - é aquela considerada pelo autor como sendo a mais importante. Tal ilusão "[...] consiste em negar ou minimizar as tensões e até mesmo as contradições internas das teorias dos direitos humanos" (p. 21). É imprescindível considerar que, ao longo dos anos, os direitos humanos foram incorporados nas instituições e nas práticas sociais de diferentes países, sendo transformados em direitos de cidadania garantidos e aplicados coercitivamente pelo Estado. Há nesse ponto um problema: em boa parte dos países - especialmente naqueles que sofreram com os regimes ditatoriais até há bem pouco tempo, como é o caso do Brasil - a prática e a defesa dos direitos de cidadania sempre foram precárias. Outra questão que mostra a natureza histórica do monolitismo reside na tensão que há entre direitos individuais e direitos coletivos. Nesse sentido, Santos argumenta que a Declaração Universal dos Direitos Humanos das Nações Unidas, de 1948, reconhece somente dois sujeitos políticos: o indivíduo e o Estado. Com efeito, povos que não tinham Estado - como os indígenas e os quilombolas, por exemplo - não foram considerados sujeitos políticos. "Assim, do ponto de vista das epistemologias do Sul, a Declaração não pode deixar de ser considerada colonialista" (p. 22).

Após ter defendido que os direitos humanos gozam de uma hegemonia que é ao mesmo tempo incontestável e frágil - já que não contribuem de forma eficaz às lutas dos oprimidos, muitas vezes chegando a atrapalhá-las -, Santos destaca a questão central sob a qual o livro se debruça: quais os desafios dos "direitos humanos quando confrontados com os movimentos que reivindicam a presença da religião 
na esfera pública"? (p. 27). A tese do autor parte do princípio de que a gramática hegemônica de direitos humanos não é capaz de enfrentar tais desafios e tampouco se dá conta da necessidade de fazê-lo. Nesse sentido, apenas uma concepção contra-hegemônica de direitos humanos seria capaz de fazê-lo. Cabe destacar então a distinção feita por Santos - no Capítulo 1 - entre concepções hegemônicas, não hegemônicas e contra-hegemônicas de direitos humanos.

Na perspectiva do autor, há no mundo uma rede global que reivindica a religião como elemento constitutivo da vida pública. Tal rede está articulada em torno de duas globalizações diferentes: a neoliberal hegemônica e a globalização contra-hegemônica. A primeira delas é, na verdade, a nova fase do capitalismo, caracterizada pela

primazia do princípio do mercado, liberalização do comércio, privatização da economia, desregulação do capital financeiro, precariedade das relações de trabalho, degradação da proteção social, exploração irresponsável dos recursos naturais etc. (p. 30).

Em contrapartida, a globalização contra-hegemônica é formada por movimentos e organizações sociais que se articulam em nível local, nacional ou global, na luta contra a opressão capitalista e colonialista, contra as discriminações raciais e sexuais, contra a exploração do meio ambiente, contra a violência e a expulsão dos povos indígenas e quilombolas de suas terras etc. Na visão de Boaventura, há um nítido embate entre essas duas formas de globalização. Todavia, para além dessa dicotomia existem reivindicações sociais que não são nem hegemônicas nem contra-hegemônicas. Tais atuações sociais lutam contra formas hegemônicas de dominação, contudo, buscam substituí-las por modelos que mantêm ou agravam ainda mais as desigualdades e as discriminações sociais.

Com base nessa distinção, argumenta que as teologias fundamentalistas, as quais pregam a substituição do Estado secular pelo Estado religioso, calcado em uma só religião, constituem discursos não hegemônicos, uma vez que não buscam acabar com as desigualdades religiosas. Por outro lado, as teologias pluralistas progressistas concebem a revelação (as escrituras sagradas) como elemento importante para a vida pública e para a organização política da sociedade, mas respeitam a autonomia entre Estado e sociedade civil. Assim, as teologias pluralistas podem ser vistas como contra-hegemônicas.

No Capítulo 2, Boaventura Sousa Santos dedica-se à análise do caso do fundamentalismo islâmico. Para o autor, as teologias políticas não ocidentais - sobretudo antiocidentais - apresentam desafios especiais à categorização hegemônico/contra-hegemônico/não hegemônico. Isso acontece em decorrência de as religiões antiocidentais não serem apenas religiões, mas antes teologias políticas. A primeira 
dificuldade em analisar tais teologias reside no fato de que a postura antiocidental que defendem não implica uma ruptura ou uma negação radical dos princípios ocidentais. Várias das diferentes teologias islâmicas incorporam elementos da cultura ocidental à sua esfera política, científica, econômica etc. A segunda dificuldade em analisar as teologias islâmicas está no próprio modo como a visão ocidental as concebe, sobretudo sob o rótulo de "fundamentalistas". Nesse sentido, Santos toma como exemplo o Islã: se, por um lado, as tendências islâmicas mais extremistas - que são minoria - pregam o ódio e as ações violentas contra o Ocidente, as tendências moderadas - que somam a grande maioria - estão preocupadas em desenvolver importantes trabalhos voluntários "na educação, saúde e bem-estar social, naquilo que pode considerar-se um projeto islâmico de modernização" ( $p$. 55). Com efeito, se os fundamentalistas islâmicos se afastam daquilo que Santos concebe como globalização contra-hegemônica, muitas das ações praticadas por islâmicos não extremistas podem ser categorizadas como contra-hegemônicas.

Nessa linha de raciocínio, no Capítulo 3 Boaventura faz uma análise do fundamentalismo cristão.

\footnotetext{
Se o fundamentalismo islâmico levanta questões relacionadas com a rejeição da modernidade ocidental, a interpretação estática da xariá, a incompatibilidade com regimes democráticos e com os direitos das mulheres, o mesmo acontece, ainda que de formas diversas, com o fundamentalismo cristão, sobretudo o protestante, reemergente nos anos 1980, nos Estados Unidos da América e conhecido como "Nova Direita Cristã" (p. 65).
}

Os movimentos fundamentalistas cristãos denunciam, de um modo geral, a liberalização da família, da educação e do aborto, as quais iriam de encontro aos valores cristãos expostos nas escrituras sagradas. Como representante desses movimentos, Santos menciona o pastor batista Jerry Falwell, que, na década de 1980, discursava em favor da proteção da família, da autoridade parental, da restauração da oração voluntária em escolas públicas etc. Além disso, Falwell também era contrário à igualdade de direitos, à revolução feminista e à revolução homossexual. Dessa forma, a Nova Direita cristã, representada pelo discurso de Falwell, buscava restaurar o "modo de vida americano", o qual deveria estar subordinado à lei de Deus, isto é, a lei do Deus cristão. Tal fundamentalismo claramente não se encaixa na categoria de discurso contra-hegemônico; antes disso, parte de uma postura não hegemônica que tenderá a aumentar as opressões e as desigualdades sociais.

No Capítulo 4, o autor destaca que a emergência das teologias políticas acaba criando novas zonas de contato entre concepções contrárias de ordem e mudança social, criando, consequentemente, turbulências políticas, culturais e ideológicas. 
A complexidade intrínseca a essas zonas tem impactado particularmente os direitos humanos. Como aproximar concepções de mundo divergentes de modo a trazê-las "a uma distância de 'contato visual'?" (p. 76). Para Santos, os direitos humanos têm se mostrado ineficazes nesse ponto. Se, por um lado, os discursos de direitos humanos têm se tornado cada vez mais inclusivos, na prática continuam a tolerar - ou a cometer - violações dos próprios princípios por eles defendidos. Essa discrepância entre a retórica e a prática dos direitos humanos concorre para o aumento da crise nas zonas de contato entre teologias políticas rivais. Consequentemente, a luta travada nas zonas de contato não raramente se torna desigual - o que pôde ser visto recentemente no conflito entre israelenses e palestinos, ou ainda na destruição do Oriente Médio cometida por países como os Estados Unidos. Conforme as palavras do autor:

\footnotetext{
Os povos que entraram na zona de contato com a modernidade ocidental fizeram-no em condições de inferioridade forçada, como foi tipicamente o caso do colonialismo. Muitos foram forçados a abandonar as concepções que os tinham guiado antes de chegar à zona de contato, outros adotaram de modo mais ou menos voluntário os novos princípios ou apropriaram-se deles conferindo-lhes novos sentidos (p. 79).
}

Após estas reflexões, o Capítulo 5 traz a seguinte pergunta: serão possíveis outros direitos humanos? Para Santos, apesar das várias fragilidades apresentadas pelos direitos humanos, isso não quer dizer que eles devam simplesmente ser descartados. Ao contrário, nunca foi tão importante conservar ideias e práticas de resistência. Nesse sentido, reconhecer as debilidades dos direitos humanos é o ponto de partida para que se construam, para além dessas fragilidades, práticas fortes de resistência. Faz-se necessário - à luz dos desafios postos aos direitos humanos hoje, sobretudo pelas teologias políticas - reinventar os direitos humanos, transformando-os em poderosas ferramentas de emancipação social, em diferentes contextos sociais. $\mathrm{Na}$ mesma proporção, faz-se necessário também identificar concepções alternativas de dignidade humana, as quais possam dialogar entre si, criando aquilo que Santos define como "ecologia de saberes", que tem por objetivo: "ampliar a legitimidade intelectual das lutas pela dignidade humana" (p. 101).

Seguindo essa linha de raciocínio, no Capítulo 6 Boaventura reafirma sua defesa por uma concepção contra-hegemônica dos direitos humanos, os quais "só podem ser imaginados como lutas contra o sofrimento injusto, concebido no sentido mais amplo e abrangendo a natureza como parte integrante da humanidade" (p. 105). No que se refere mais precisamente à relação entre direitos humanos e religião, o autor defende que o diálogo entre as teologias pluralistas é um provável bom caminho para desenvolver práticas eficazmente emancipatórias. 
Por fim, Boaventura responde à pergunta metafórica que dá título ao livro: e se Deus fosse um ativista dos direitos humanos?

\begin{abstract}
Se Deus fosse um ativista dos direitos humanos, Ele ou Ela estariam definitivamente em busca de uma concepção contra-hegemônica de direitos humanos e de uma prática coerente com ela. Ao fazê-lo, mais tarde ou mais cedo este Deus confrontaria o Deus invocado pelos opressores e não encontraria nenhuma afinidade com Este ou Esta (p. 142).
\end{abstract}

Pode-se afirmar que "se Deus fosse um ativista dos direitos humanos" alcançaria o objetivo a que se propunha. Boaventura de Sousa Santos conseguiu desconstruir a perspectiva tradicional acerca dos direitos humanos, demonstrando que estes, ao mesmo tempo em que gozam de uma hegemonia social incontestável, são frágeis e falhos em sua tarefa básica: diminuir as desigualdades e garantir os direitos dos oprimidos no âmbito das sociedades.

Fragilidade esta que se evidencia especialmente no que tange às tensões entre as diferentes e rivais teologias políticas. Mas Santos não se limita a apenas expor as debilidades intrínsecas aos direitos humanos, vai além, e propõe um caminho alternativo, o qual reconhece a importância de serem incorporadas novas linguagens de dignidade humana, as quais têm sido ignoradas pelos discursos de direitos humanos. Essa reestruturação dos direitos humanos é de fato necessária para sustentar a luta desigual travada por movimentos e organizações sociais contra o neoliberalismo, o patriarcalismo e o colonialismo. Assim, construir uma concepção contra-hegemônica de direitos humanos, tal como defende Santos, é condição sine qua non para a construção efetiva de uma democracia radical. 